\title{
Efficacy of Muscle Energy Technique on Functional Ability of Shoulder in Adhesive Capsulitis
}

\section{Narayan, Anupama ${ }^{1}$, Jagga, Vinay ${ }^{2}$.}

${ }^{1}$ Prem Physiotherapy \& Rehabilitation College, Panipat, Haryana, India. E-mail: dranupamaphysio@gmail.com

${ }^{2}$ Associate Professor and Head, Prem Physiotherapy \& Rehabilitation College, Panipat, Haryana, India. Email: jaggavinay04@gmail.com

*Correspondending Author: Narayan, Anupama, M.P.T Student, Prem Physiotherapy \& Rehabilitation College, Panipat, Haryana, India. E-mail: dranupamaphysio@gmail.com

Abstract
Adhesive Capsulitis is a very painful condition of the shoulder characterized by pain, severe
stiffness and movement restriction usually present in the sixth decade of life. Onset before age
40yr is uncommon. The non dominant shoulder is slightly more likely to be affected. Muscle
energy (MET) technique is very much beneficial in this condition. Muscle energy techniques are
class of soft tissue osteopathic manipulation consisting of isometric contraction design to improve
musculoskeletal function and reduce pain. Method:-30 patients of Adhesive Capsulitis were
included in the study using convenient random sampling divided into 2 groups, Group A
(Experimental) and Group B (Control). Each group was divided into 15 patients. 40 - 60 year old
patients of both genders were included in the study. Control group was treated with conventional
physiotherapy treatment. The Experimental group was treated with MET for shoulder Flexion,
Abduction, and External rotation along with Conventional treatment. Result: Both Groups
showed significant difference and improvement after treatment. There is significant difference in
Post test scoring of both the groups; with lower SPADI scoring
Group A of experimental group shows better results then Group B of control group. Conclusion:
Muscle energy technique is very much effective on functional ability of shoulder in adhesive
Capsulitis.
Key Words: Frozen Shoulder, Codmen Exercise, Hot Packs.

\section{Introduction}

Adhesive capsulitis is a condition of the shoulder of unknown etiology. It is characterized by pain and restriction of both passive and active range of motion (ROM). Duplay referred to Adhesive capsulitis in 1872 as "Scapulohumeral Periarthritis," a disorder he believed resulted from subacromial bursitis (Post, 1978; Neviaser, 1980; Bruckner \& Nye, 1981; Jayson, 1981; Kessel et al, 1981; Rizk \& Pinals, 1982; Loyd \& Loyd, 1983; Griggs et al, 2000; Patil et al, 2010, Day \& Nitz, 2012). In 1934, Codman coined the term "frozen shoulder" but used it in association with tendinitis of the rotator cuff (Kessel et al, 1981).

Neviaser (1983) introduced the concept of adhesive capsulitis when he discovered that the capsule was tight, thickened, and stuck to the humerus in such a manner that it could be peeled off like "adhesive plaster from the skin (Post, 1978; Jayson, 1981; Loyd \& Loyd, 1983; Rizk et al, 1983; Schenk et al, 1997; Sandy et al, 2006; Steples et al, 2010; Stephanie et al, 2011; Srikanth et al, 2013). Loyd and Loyd (1983) suggested that secondary frozen shoulder develops when painful spasm limits activity and creates dependency of the arm. 
Adhesive capsulitis is a commonly recognized but poorly understood cause of a painful and stiff shoulder. Although most orthopaedic literature supports treatment with physical therapy and stretching exercises, some studies have demonstrated late pain and functional deficits. The purpose of these studies was to evaluate the outcome of patients with adhesive capsulitis who were treated with a stretching-exercise program as reported by Griggs et al, (2000). Staples et al (2010) concluded that the shoulder pain and disability index (SPADI) is superior responsiveness when compared to the Disability arm, shoulder, hand (DASH) in patient with adhesive capsulitis.

Muscle energy techniques (MET) are a class of soft tissue osteopathic manipulation methods that incorporate precisely directed and controlled patient initiated, isometric contractions, designed to improve musculoskeletal function and reduce pain. Schenk et al, (1997) modelled this study found that lumbar extension was significantly increased after treatment, supporting MET as an appropriate therapy for restoring lumbar extension ROM. The authors recommended further MET efficacy studies be undertaken focussing on the thoracic and sacroiliac regions. Stephanie et al (2011) conducted a study to compare the muscle energy technique for the glenohumral joint external rotators to improve glenohumeral joint range of motion in baseball players. Their result showed that single application of and Muscle energy technique (MET) for the Glenohumeral joint horizontal abductors provided immediate improvement in both GHJ horizontal adduction and internal rotation ROM in asymptomatic collegiate baseball players. Srikanth et al (2013) did a study to compare the effectiveness of anterior versus posterior glide mobilization techniques and improving functional activity of the shoulder in patient with adhesive capsulitis. Patel et al (2010); conducted the study to compare the effectiveness of MET on quadratus lumborum in acute low back using a randomized control trial. They studied a total number of 40 subjects (21 male and 19 female) and the result of the study concluded that MET on quadrates lumborum combined with interferential therapy is more effective in reduction of disability and increasing spinal range of motion than interferential therapy alone in patients with acute low back pain. The aim of the present study was to study the effectivity of MET on functional ability of shoulder in Adhesive Capsulitis.

\section{Materials and Methods}

30 patients of Adhesive Capsulitis were included in the study using convenient random sampling from Delhi NCR and further divided into 2 groups, Group A (Experimental) and Group B (Control). Each group was divided into 15 patients. 40 - 60 year old patients of both genders were included in the study. Patients with Rotator cuff tear, any systemic disorder any neurological disorder or fracture in and around shoulder were excluded. Control group was treated with conventional physiotherapy treatment which consisted of Ultrasound Therapy, Hot pack, Codman's exercises, Pulley exercises and active assisted exercises. The Experimental group was treated with MET for shoulder Flexion, Abduction, and External rotation along with Conventional treatment. The protocol for 
MET to shoulder joint included 3 repetitions per set, 1 session per day and thrice a week for 5 weeks.

\section{Results \& Discussion}

Statistical comparison of the two groups, Experimental (group A) and Control (group B) reveal no significant differences in the mean age of both groups. Statistics were performed by using SPSS 13. Results were calculated by using 0.05 level of significance.

Table 1: Statistical comparison of mean scores of Shoulder pain and disability index before and after the treatment in the experimental group

\begin{tabular}{lllll}
\hline $\begin{array}{l}\text { Experimental } \\
\text { Group }\end{array}$ & MEAN & \pm SD & T & P \\
\hline Pre & $\mathbf{5 6 . 5 3}$ & $\mathbf{1 5 . 9 6}$ & \multirow{2}{*}{9.22} & $<\mathbf{0 . 0 5}$ \\
\hline Post & $\mathbf{3 7 . 5 3}$ & $\mathbf{1 1 . 7 4}$ & & \\
\hline
\end{tabular}

Table 2: Statistical comparison of mean scores of Shoulder pain and disability index before and after the treatment in the control group

\begin{tabular}{lllll}
\hline $\begin{array}{l}\text { Control } \\
\text { Group }\end{array}$ & MEAN & \pm SD & T & P \\
\cline { 1 - 3 } Pre & 63.07 & 10.60 & 11.82 & $<0.05$ \\
\hline Post & 46.87 & 10.46 & & \\
\hline
\end{tabular}

Group A was given MET with Conventional treatment. The Pre treatment scoring of SPADI is $56.53 \pm$ 15.96 and Post 37.53 \pm 11.74 . Group B was given Conventional treatment. The Pre treatment scoring of SPADI is 63.07 10.60 and Post was 46.87 \pm 10.46 .

Both the groups showed significant difference and improvement after treatment. However, greater magnitude of $\%$ improvement was observed in the Group A i.e. the experimental group than the Group B of control group.

\section{Discussion-}

The purpose of this study was to see the Efficacy of Muscle energy technique on Functional ability of Shoulder in Adhesive Capsulitis. In this study age distribution showed no significant difference in both groups. The comparison of mean value of age in Group A is $50.80 \pm 6.48$ yrs and Group B is $51.13 \pm 5.77$ yrs. Group A showed significant changes may be due to the application of MET that relaxes and improve biomechanics and thus results in improved functional ability. Group B also showed mild changes due to the relaxation effect of conventional treatment. It was evident from the mean score that both the groups showed improvement in SPADI score because of treatments. Between groups analysis revealed that percentage of improvement in SPADI score was more in shoulder MET group which further showed more improvement than the conventional treatment Group.

The data analysis and statistic inference have brought to check the effectiveness of MET and conventional treatment on the variables of the study which are pain, functional ability and ROM . The MET has an effect in reducing pain, increase ROM and functional ability in patient with adhesive Capsulitis. This is also supported by the study of Patil et al (2010). They took 40 subjects (21 males and 19 females) diagnosed with acute low back pain. Subjects were randomly assigned to two groups of 20 each. The control group received interferential therapy while interventional group received MET on quadratus lumborum combined with interferential therapy. MET on quadratus lumborum combined with IFT demonstrated a statistically significant difference $(\mathrm{p}<0.001)$ showing decrease in disability and increase in 
spinal range of motion than IFT alone. In the present study Muscle energy technique along with conventional treatment is found to be relatively more effective on pain, disability and ROM than the conventional treatment alone. The study of Day et al (2012) also supports the results of the present study. Low back pain is the most common type of pain reported by adults in the United States. A variety of manual therapy techniques are being used in the management of low back pain to reduce pain, improve function, and reduce disability. Muscle energy techniques have been increasingly used in clinics to treat low back pain Day et al (2012).

Akbari et al (2012) reported a study in which thirty patients with trigger points in the upper trapezius and levator scapula were randomly assigned to one of the three groups in equal number. In the laser group a low level Ga- As laser was applied with pulse duration of $200 \mathrm{~ns}$ and $60 \mathrm{j} / \mathrm{cm} 2$ dosages by contrast in the muscle energy group, in the present study used stretching following Post isometric relaxation and in the placebo group used low level laser without an output. The result showed that low level laser and muscle energy technique are both equally effective in decreasing the neck and shoulder pain and disability in patients with myofascial trigger points in trapezius and levator scapula muscle (Akbari et al, 2012). There effect was reported to be beneficial because these exercises spread synovial fluid stimulate tonically depressed joint mechanoreceptors, alleviate pain secondary to muscle ischemia or prevent collagen cross bridging. These results of study are also supported by the study Schenk et al
(1997) in their study on physical therapy management of the shoulder. Subject in the present study have similar baseline values of all dependent variables suggesting that both groups had similar distribution of patients. Statistical analysis reveals that there are significant changes in all the base values. These include decrease in pain, improvement in the Disability score, increase in ROM. Group A demonstrated significant changes that may be ascribed to the usage of the MET that relaxes and improve biomechanics and thus may result in increase in ROM, decrease in pain and improvement in the functional ability. Group B also showed some significant changes may be due to the relaxation effect of conventional treatment that may have caused improvement in ROM, SPADI and VAS. Between the groups analysis revealed that percentage of improvement in pain in Group A was greater than Group B.

Our data supported alternate hypothesis that shoulder Muscle energy technique along with conventional treatment for functional ability in adhesive capsulitis was more effective than the shoulder conventional treatment for functional ability in Adhesive capsulitis.

Conclusion: Muscle energy technique is very much effective on functional ability of shoulder in adhesive Capsulitis.

\section{References}

Akbari, A.; Naroii, S.H.; Eshgi, M.; Farahani, A. 2012. A Comparision between Muscle energy technique with lower level Laser in Reducing neck and shoulder pain and disability in subject with Trapezius' and Levator scapula Myofascial Trigger Points, 20(79): 69-82.

Bruckner, F.E.; Nye, C.J. 1981. A prospective study of adhesive capsulitis of the shoulder 
("frozen shoulder") in a high risk population. Q. J. Med., 50: 191-204,

Day, J.M.; Nitz, A.J. 2012. The effect of muscle energy techniques on disability and pain scores in individuals with low back pain. J Sport Rehabil., 21(2): 194-8

Griggs, S.M.; Ahn, A.; Green, A. 2000. A prospective functional outcome study of nonoperative treatment. J. Bone Joint Surg. Am. 82A(10): 1398- 407.

Jayson, M.1. 1981. Frozen shoulder: Adhesive capsulitis. Br. Med. J. [Clin. Res.], 283:10051006 ,

Kessel, L.; Bayley, I.; Young, A. 1981. The upper limb: The frozen shoulder. Br. J. Hosp. Med, 25: 334

Loyd, J.A.; Loyd, H.M. 1983. Adhesive capsulitis of the shoulder: Arthrographic diagnosis and treatment. South Med. J., 76: 879-883.

Loyd, J.A.; Loyd, H.M. 1981. Adhesive capsulitis of the shoulder: Arthrographic diagnosis and treatment. South Med. J., 336-337.

Neviaser, J.S. 1980. Adhesive capsulitis and the stiff and painful shoulder. Orthop. Clin. North Am., 11: 327-333.

Patil, Prachi N.; Basavaraj, Chandu; Metgud, Santosh; Khatri, Subhash. 2010. Effectiveness of muscle energy technique on quadratus lumborum in acute low back painrandomized controlled trial. Indian journal of Physiotherapy and Occupational Therapy; 4: 58.

Post, M (ed): 1978. The Shoulder: Surgical and Nonsurgical Management. Philadelphia, PA, Lea \& Febiger,
Rizk, T.E., Pinals, R.S. 1982. Frozen shoulder. Semin. Arthritis Rheum., 11: 440-452,

Rizk, T. E.; Christopher, R. P.; Pinals, R. S.; Higgins, A. C.; Frix, R. 1983. Adhesive capsulitis (frozen shoulder): A new approach to its management. Arch. Phys. Med. Rehabil., 64: $29-33$

Steples. M.P.; Forbes, A.; Green, S.; Buchbinder, R. 2010. Shoulder.Specific disability measures showed aceeptable construct validity and responsiveness J. Clin. Epidemiol, 63: 163.170 .

Schenk, R.; MacDiarmid, A.; Rousselle, J. 1997. The Effects of Muscle Energy Technique on Lumbar Range of Motion. Journal of Manual and Manipulative Therapy. 5(4): 179 - 183.

Sandy, Fritz; Gary, Fryer; Ken, Crenshaw; Craig, Liebenson et al. 2006. Leon Chaitow Muscle Energy Techniques; $3^{\text {rd }}$ Edition; Churchill living stone publications; p.341.

Stephanie, D., Moore, M.S., ATC1 - Kevin G. Laudner, Todd, A. Mcloda, Michael, A. Shaffer, P.T. 2011. The Immediate Effects of Muscle Energy Technique on Posterior Shoulder Tightness: A Randomized Controlled Trial. J. Orthop. \& Sports Physical Therapy, 41: 407.

Srikanth, Babu V.; Srinivas, M.; Ravindra Kumar B.; and Jalaja Prakash. 2013. The effects of Anterior versus Posterior Glide joint Mobilization in Improving Functional Activity of the shoulder in Patients with adhesive capsulitis; Int. Res. J. Biological Sci. 2(1): 1521. 